\title{
VENTAJAS DELAPRENDIZAJE COOPERATIVO PARA EL LOGRO DE CONDUCTAS ADAPTATIVAS DE LAS PERSONAS CON DISCAPACIDAD INTELECTUAL
}

\author{
Lic.Ledda SchwarzAguayo
}

\begin{abstract}
RESUMEN
Se aborda el tema de las ventajas del aprendizaje cooperativo que contribuye a potenciar el aprendizaje y el desarrollo de habilidades de la persona con discapacidad intelectual, dentro de un trabajo cooperativo que estimula el logro de objetivos, desarrollando una actitud positiva dentro de un clima integrativo entre los estudiantes.
\end{abstract}

\section{ABSTRACT}

lt is about the cooperative learning advantages which contribute to boost learning and abilities development of a person with intellectual disability in a cooperative work which stimulates the objective achievement, developing a positive attitude of an integrative environment among thestudents.

\section{PALABRAS CLAVE}

Discapacidad intelectual, conducta adaptativa, aprendizaje, discapacidad intelectual, aprendizaje coo pe rat ivo.

\section{KEYWORDS}

Intellectual disability, adaptive behavior, learning, intellectual disability, cooperative learning.

\section{ANTECEDENTES}

1 nt es del siglo XIX, la concepción de la discapacidad intelectual era considerada como una variable de la demencia, atribuida a causas orgánicas, biológicas o innatas, entre otras.

Es a partir del siglo XIX que se diferencia la discapacidad intelectual de la demencia y otras patologías. En 1959, la Asociación Americana sobre Personas con Deficiencia Mental (AAMD) y que en los albores de los años ochenta se denominó Asociación Americana sobre Personas con Retraso Mental (AAMR), puntualizaron la mayor aceptación en los medios científicos y profesionales.

En el siglo XX, la definición sobre el concepto de Deficiencia Intelectual ha sido unificada después de profundos estudios sobre el tema. Inicialmente, el criterio psicológico era el predominante y el más obvio era el nivel de inteligencia y lo confirmaron con la apreciación psicométrica que tenía en cuenta, básicamente, el cociente intelectual C.I y algunos rasgos de la competencia social.

En 1983, la Asociación Americana sobre Personas con Deficiencia Mental propone la definición de Grossman: "El retraso mental se refiere a un funcionamiento intelectual general significativamente inferior a la media que resulta o va asociado con déficits concurrentes en la conducta adaptativa y que se manifiesta durante el período de desarrollo"1

Es así como el concepto de la conducta adaptativa recibe una mayor atención para identificar la discapacidad intelectual.

Se criticó la factibilidad de las pruebas de inteligencia que dependían más del conocimiento adquirido que de la facultad de aprender .

\section{ss $\mid$ un1Fé}


En la actualidad, la concepc1on sobre conducta adaptativa como criterio de identificación de la discapacidad intelectual es predominante. El déficit de la conducta adaptativa se refiere "a la calidad del funcionamiento diario afrontando las demandas ambientales" 2 . Esto es definido expresamente como "limitaciones significativas en la eficacia individual en satisfacer los patrones de maduración, aprendizaje, independencia personal y responsabilidad social esperados para su edad y grupo cultural tal como se determinan por evaluación clínica y, frecuentemente, por escalas estandarizadas" 3

Es importante mencionar el planteamiento sobre la clasificación de la conducta en tres etapas evolutivas diferentes (Grosmann, 1983) que menciona M. A. Verdugo en su escrito sobre La conducta adaptativa yel enfoque multidimensional de la persona con discapacidad intclectual. $^{4}$

A Durante la infancia o la nmez temprana: desarrollo de habilidades sensoriomotrices, de comunicación, de autoayuda y de socialización.

B. Durante la niñez y adolescencia temprana: aplicación de habilidades académicas básicas a la vida diaria. Aplicación de juicio y razonamiento apropiados en el dominio del ambiente y habilidades sociales; y

C. Durante la adolescencia tardía y la edad adulta: ejecuciones $\mathrm{y}$ responsabilidades sociales y profesionales.

\section{NUEVO ENFOQUE: VENTAJAS}

Este nuevo enfoque que prioriza la conducta adaptativa, pretende mejorar los sistemas de atención profesional al deficiente intelectual y potenciar el aprendizaje apoyando su interacción con el medio y las personas que lo rodean en su contexto cotidiano.

Esta interacción se convierte en fuente importante de aprendizaje tanto a nivel cognitivo como afectivo, permitiéndoles desarrollar habilidades y actitudes positivas frente al trabajo y hacía su vida personal.

Un beneficio adicional y no por ello menos importante, es que este nuevo enfoque sobre la concepción de la discapacidad intelectual puede permitir alcanzar la meta de la educación inclusiva. Reconoce que los problemas de aprendizaje son contextuales y que los docentes podrían, por lo tanto, usar diferentes modalidades de trabajo con la finalidad de que el niño o joven con discapacidad intelectual, experimente diversas situaciones de aprendizaje que le sirvan para poder afrontar problemas diarios.

Entre las modalidades que el docente puede utilizar en clase están el trabajo individual, en pares y en pequeños grupos, posibilitándole el que puedan desarrollar diferentes habilidades cognitivas y sociales, a través de múltiples estrategias de aprendizaje, dándole especial importancia al trabajo cooperativo.

\section{APRENDIZAJE COOPERATIVO}

Es aquel que se caracteriza por permitir una interdependencia positiva entre los alumnos. Esta interdependencia positiva ocurre cuando cada uno de ellos percibe que está unido a otros, de tal suerte que al coordinar sus esfuerzo s con los demás, logra obtener un mejor producto y así poder completar una tarea de manera más exitosa . El aprendizaje, por lo tanto, tiene lugar a través de la ense ñanza de los compañeros, de la solución de problemas conjuntos y de una variable comunicación interper sonal.

Cabe destacar, que la consecución de estos objetivos tiene como base el proceso de cooperación, es decir, el dar y recibir ideas, proveer ayuda y asistencia, intercambiar los recursos necesarios y el aportar con críticas constructivas.

Este método ha causado un gran impacto en la educación en los últimos tiempos y puede ser usado estratégicamente en la educación de las personas con necesidades educativas especiales (NEE) en las escuelas de inclusión. Este tipo de aprendizaje ofrece beneficios puntuales para un mejor desempeño integral.

\section{BENEFICIOS}

Entre los más notables tenemos:

Desarrollar actitudes posi t ivas hacía el aprendiza je.

Aumentar la motivación yla autoestima.

Promover el respeto entre sus pares.

Promover las relaciones interpersonales.

Desarrollar la tolerancia, la flexibilidad y la

apertura hacia los demás.

Enseñar a compartir responsabilidades.

Enseñar a organizarse y a dividir las tareas y roles 
para lograrun mejor resultado.

Permitir una mayor riqueza en el aprendizaje de los diferentes contenidos.

Permitir potenciar sus habilidades personales.

Esta interacción en el aspecto social les permitirá una mayor adaptabilidad a su contexto y al mejor desenvolvimiento en su mundo cotidiano.

Desde la perspectiva docente y en el marco del aprendizaje cooperativo, se deben alcanzar ciertos requerimientos, tales como:

Plantear objetivos específicos a ser alcanzados y describir con mucha precisión lo que se espera que aprendan.

Lograr que acuerden los alumnos sobre los pasos de lo que deben hacer, qué materiales necesitan y otros.

Organizar grupos y rotados cada cierto tiempo a fin de que se conozcan y aprendan a aceptar sus diferentes maneras de pensar y trabajar.

Comprometer a los alumnos a que sean capaces de comprenderse, aceptarse y respetarse con sus habilidades, potencialidadesy debilidades.

Evaluar el nivel de participación del grupo y de cada integrante en particular.

Consideramos que esta propuesta fortalece el mantenimiento del grupo, facilita la adquisición y la práctica de capacidades que, a su vez, permitirá un desarrollo eficaz de las habilidades sociales, incluyendo el inicio, el mantenimiento y la finalización de una interacción con otros, así como reconocer afectos, regular el comportamiento, tener conciencia dela existencia deiguales y su aceptación, ayudar a otros, mantener y hacer amistades, afrontar las demandas de otros, controlar impulsos, comportarse armónicamente en lo social y en lo sexual, asi como lograr una inclusión a futuro en el aspecto ocupacional.

Finalmente, un enfoque interactivo y de cooperación no solo tendrá en cuenta los factores ambientales, sino también las capacidades y las potencialidades que les permitirán a las personas con dificultades intelectuales una tarea con éxito.

\section{NOTAS}

(I) Grossman,p. 9.

(2) Grossman, p. 42.

(3) lbid, p. 11.

\section{REFERENCIAS}

GordenPorter(2000).Laeducacióninclusiva.Perú:IPAE.

Tregold Soddy. El subnormal en lacomunidad.
(4) Verdugo, M. A. (1999). La conducta adaptativa y el enfoque multidimensional. Separata.

Lic. Ledda Schwarz Aguayo

Docente especialista en Educación Especial, área: discapacidad mental. Cuenta con una vasta experiencia y ha desempeñado diversas responsabilidades jerárquicas, además es docente de la Universidad Femenina del Sagrado Corazón. 